\title{
Isolation and Characterization of Flavonoid and Other Compounds from Seeds Extract of Calpurnia Aurea
}

\author{
Tariku Nefo*1 Tamirat Dula ${ }^{2} \quad$ Bazabih Kelta $^{3} \quad$ Kiros Haile $^{4}$ \\ Department of Chemistry, College of Natural and Computational Sciences, University of Wolaita Sodo, P.O. \\ Box, 138, Ethiopia
}

\begin{abstract}
The study was undertaken to isolate and characterize flavonoid and other compounds from seeds extract of Calpurnia aurea. Three compounds were isolated from this medicinal plant, it were identified as flavonoid compound G1 named: 2-(4-(2-hydroxyethyl)phenyl)-4H-chromen-4-one, compound P2 named: 1-(2-(3-((E)-buta1,3-dienyl) cyclopentyl)ethyl)benzene and compound C3 named: (E)-methyl 14-hydroxy-10-methyltetradec-2enoate. Its structures determinations were based on ${ }^{1} \mathrm{H},{ }^{13} \mathrm{C}$ NMR spectral measurements. In this study, proton and carbon signals were assigned by means of 2D NMR spectral methods for compound P2.
\end{abstract}

Keywords: 2D NMR; Calpurnia aurea; Phytochemical; Structure

DOI: $10.7176 / \mathrm{JNSR} / 9-7-01$

Publication date: April $30^{\text {th }} 2019$

\section{Introduction}

Background of the study

Natural products chemistry is a distinct area of chemical research which was important in the history of chemistry, the sourcing of substances in early preclinical drug discovery research, the understanding of traditional medicine and ethno pharmacology, the evolution of technology associated with chemical separations, the development of modern methods in chemical structure determination by NMR and other techniques, and in identification of pharmacologically useful areas of chemical diversity space $[1,2,3]$. Calpurnia aurea is an African medicinal plant used in many countries in Africa to treat a range of medical conditions or disorders. Extracts of the plant were shown to be active in antibacterial and antioxidant assays as well as against lice, ticks and maggots. The aim of the study was to isolate the phytochemical constituents from the plant and to test them in appropriate bioassays dependent on the compounds isolated in order to provide a rationale for the use of the plant in ethno-medicine or to provide some information on its constituents [4]. It is evident from this study that highest therapeutic efficacy possessing majority of secondary metabolites classes of compounds in both leaves and seeds of Calpurnia aurea, which can be quantified for application in pharmaceutical industry. Conversely seeds contain more alkaloids and tannins than the leaves of Calpurnia aurea [5].

In Ethiopia, Calpurnia aurea is used for the treatment of syphilis, malaria, rabies, diabetes, hypertension, diarrhoea, leishmaniasis, trachoma, elephantiasis, fungal disease and different swellings. However, despite its traditional usage as an antidiarrhoeal and antimicrobial agent, there is limited or no information regarding its effectiveness and mode of action in diarrhoea which may be caused by Shigella flexneri, Staphylococcus aureus, Escherichia coli and Salmonella typhi. Hence, we evaluated the $80 \%$ methanol (MeOH) extract of the dried and powdered leaves of $C$. aurea for its antidiarrhoeal and antimicrobial activities; in general Calpurnia aurea possesses good anti diarrheal and antimicrobial activity which support the traditional use of the plant in the treatment of diarrhea in Ethiopia [6]. The isoflavones, 4',5,7-trihydroxyisoflavone (1), 7,3'-dihydroxy-5' methoxy iso flavone (2), 7-hydroxy-4',8-dimethoxy iso flavone (3), 7- acetoxy-4',8-dimethoxy isoflavone (4) and 3',7dihydroxy-4',8-dimethoxy isoflavones (5), a pterocarpan (3-acetoxy-9 methoxy pterocarpan) and a quinolizidine alkaloid (calpurnine) were isolated from the stem and bark of Calpurnia aurea. The tetrasubstituted isoflavone (5) was found to be the most active in the three cell lines among all the compounds tested. This was followed by trisubstituted isoflavone, (2); this isolation and characterization of isoflavone done in Durban, South Africa [7].

Calpurnia aurea leaves and seed were containing tannins, flavonoids, terpenoids, saponins, steroids, glycosides, alkaloids but absent anthraquinone, yet seed containing more tannins and alkaloids than the leaves. Flavones and polyphenol levels were found more in leaves than the seeds. The extracts of both leaves and seeds of the plant indicated strong antioxidant activities [8]. The medicinal plants are useful for healing as well as for curing of human diseases because of the presence of phytochemical constituents [9].

\section{Materials and method}

\section{Plant collection and identification}

The seeds of Calpurnia aurea were collected from southern nations, nationalities, and peoples' region of Ethiopia around Wolaita Sodo University campus, which is $333.5 \mathrm{~km}$, south of Addis Ababa. The plant was identified by botanists in the department of biology, Wolaita Sodo University. 


\section{Extraction and isolation}

Compound G1, the collected seeds were washed thoroughly in tap water, shade dried and pulverized. Compound G1 was extracted using $30 \mathrm{~g}$ of pulverized plant material and was extracted with $180 \mathrm{ml}$ of petroleum ether in a shaker for 24 hours. The solid residue obtained was then treated with ethyl acetate for 24 hours and filtered. The resulting filtrate was concentrated using flash evaporator for complete solvent removal. The freeze dried material was extracted with boiling acetone and the residue was concentrated at atmospheric pressure. This concentrated residue was extracted successively with light petroleum ether and benzene to remove non flavonoid and other matter.

Compound P2, the air-dried seeds of Calpurnia aurea $(250 \mathrm{~g})$ were extracted with one liter of methanol. The MeOH soluble crude (11.2 g) was chromatographed on silica gel (200 g) using gradient elution with methanolchloroform (10:1 to 1:1). Compound P2 (51.23 mg) was obtained from the methanol- chloroform (2:8) fraction.

Compound C3, the air-dried seeds of Calpurnia aurea $(200 \mathrm{~g})$ were extracted with one liter of ethyl acetate. The $\mathrm{MeOH}-\mathrm{CHCl}_{3}(1: 1)$ soluble crude $(5.5 \mathrm{~g})$ was chromatographed on silica gel $(180 \mathrm{~g})$ using gradient elution using the following solvent system starting from none polar to increasing their polarity: starting from $100 \%$ pure $n$-hexane, $n$-hexane/EtOAc $(9: 1),(8: 2),(7: 3),(6: 4),(1: 1),(4: 6)$ and (3:7) ratio and total of 37 fractions were collected. Compound C3 $(31 \mathrm{mg})$ was obtained from the $n$-hexane/EtOAc (7:3) fraction.

\section{Phytochemical screening tests}

Phytochemical screening tests were done to determine the class of compounds present in both crude extract, by following the standard procedures $[10,11]$. Table 1

Tabel 1 Phytochemical screening test results

No. Class of secondary metabolites

Calpurnia aurea seeds extract present $(+)$ and absent (-) Ethyl acetate

Alkaloid
Flavonoid
Terpenoid
Saponin
Tannin
Steroid
Anthraquinone
Phenol

Methanol
+
+
+
+
+
+
-
+
+

\section{Instruments}

NMR spectra were recorded on a Bruker Advance instrument (400 MHz and $100 \mathrm{MHz}$ ) and with TMS as an internal standard (chemical shifts in $\delta, \mathrm{ppm})$. 2D NMR (400 MHz, DMSO- $\left.d_{6}\right)$ spectra were recorded under standard conditions. The isolated compounds were dissolved in DMSO- $d_{6}$ and analyzed with 1D NMR (proton ${ }^{1} \mathrm{H}$, carbon ${ }^{13} \mathrm{C}$ ), 2D NMR (HMBC and HMQC) and LC-MS.

\section{Characterization of the compounds \\ Characterization of compound G1}

Compound $\mathrm{G} 1$ has molecular formula; $\mathrm{C}_{17} \mathrm{H}_{14} \mathrm{O}_{3}$ was determined by negative ESI-MS and NMR spectra. In the negative ESI-MS spectrum, the quasi-molecular ion peak was at $\mathrm{m} / \mathrm{z} 266.5[\mathrm{M}-\mathrm{H}]^{-}$.

The ${ }^{1} \mathrm{H}$ NMR spectrum exhibited signals for the presence of two benzene ring at $\delta_{\mathrm{H}} 7.84(1 \mathrm{H}, \mathrm{d}$,), $\delta_{\mathrm{H}} 7.57(1 \mathrm{H}, \mathrm{d}, \mathrm{d}), \delta_{\mathrm{H}} 7.21(1 \mathrm{H}, d, d), \delta_{\mathrm{H}} 7.02(1 \mathrm{H}, d)$ and $\delta_{\mathrm{H}} 7.3(2 \mathrm{H}, d), \delta_{\mathrm{H}} 7.1(2 \mathrm{H}, d)$. Two pairs of methylene proton signals at $\delta_{\mathrm{H}} 2.8(2 \mathrm{H}, \mathrm{t})$ and $3.86(2 \mathrm{H}, \mathrm{m}$, the proton signal of methylene connected to an alcohol). An alkene proton signal at $\delta_{\mathrm{H}} 6.92(1 \mathrm{H}, \mathrm{s})$.

In the ${ }^{13} \mathrm{C}$ NMR spectrum, there were seventeen carbon signals and very intense signals at $\delta_{\mathrm{C}} 128.7$ and $\delta_{\mathrm{C}}$ 127.4 each of which almost certainly represents two carbon atoms $(\mathrm{C} 13,15$ and $\mathrm{C} 12,16)$. Signals at $\delta_{\mathrm{C}} 131.7$, $124.5,136.3,118.7,158.3$ and $\delta_{\mathrm{C}} 125$ assigned for the second aromatic ring. Signal at $\delta_{\mathrm{C}} 183$ showed there was carbonyl group in the structure.

All chemical shift data in the 1D-NMR spectra agreed with the proposed structure for the compound G1: 2(4-(2-hydroxyethyl)phenyl)-4H-chromen-4-one. (See Fig 1) 


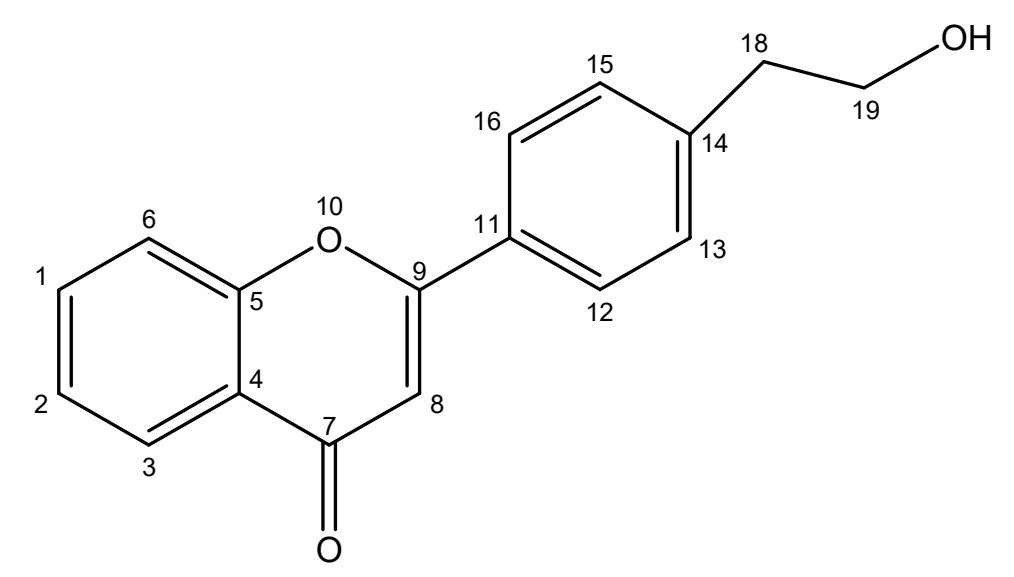

Fig. 1 The structure of compound G1

Table $1{ }^{1} \mathrm{H}$ NMR, ${ }^{13} \mathrm{C}$ NMR and DEPT-135 spectral data of compound G1 in DMSO- $d_{6}$

$\begin{array}{cccc}\text { No. } & { }^{1} \mathrm{H} \mathrm{NMR}(\mathrm{ppm}) & { }^{13} \mathrm{C} \text { NMR(ppm) } & \text { DEPT-135 } \\ 1 & 7.57(1 \mathrm{H}, \mathrm{d}, \mathrm{d}) & 136.3 & \mathrm{CH} \\ 2 & 7.21(1 \mathrm{H}, \mathrm{d}, \mathrm{d}) & 124.5 & \mathrm{CH} \\ 3 & 7.84(1 \mathrm{H}, \mathrm{d}) & 131.7 & \text { Quaternary } \\ 4 & & 125 & \text { Quaternary } \\ 5 & & 158.3 & \mathrm{CH} \\ 6 & 7.02(1 \mathrm{H}, \mathrm{d}) & 118.7 & \text { Quaternary } \\ 7 & & 183 & \text { Quaternary } \\ 8 & 6.92(1 \mathrm{H}, \mathrm{t}, \mathrm{t}) & 106 & \text { Quaternary } \\ 9 & & 164.5 & \\ 10 & & & \text { Quaternary } \\ 11 & & 128.6 & \mathrm{CH} \\ 12 & 7.3(1 \mathrm{H}, \mathrm{d}) & 127.4 & \mathrm{CH} \\ 13 & 7.1(1 \mathrm{H}, \mathrm{d}) & 128.7 & \text { Quaternary } \\ 14 & & 139.7 & \mathrm{CH} \\ 15 & 7.1(1 \mathrm{H}, \mathrm{d}) & 128.7 & \mathrm{CH} \\ 16 & 7.3(1 \mathrm{H}, \mathrm{d}) & 127.3 & \mathrm{CH} 2 \\ 18 & 2.8(2 \mathrm{H}, \mathrm{t}) & 39.3 & \mathrm{CH} \\ 19 & 3.86(2 \mathrm{H}, \mathrm{d}, \mathrm{t}) & 62.5 & \end{array}$

\section{Characterization of compound P2}

Compound P2 was obtained as a black solid from methanol extract. Its molecular formula, $\mathrm{C}_{17} \mathrm{H}_{22}$ was determined by negative LC-MS. In the negative LC-MS spectrum, the quasi-molecular ion peak was at m/z 227.06 [M-H]

In the IR ( $\mathrm{KBr}$ disk) spectrum showed absorption band at $2929 \mathrm{~cm}^{-1}$ and medium absorption band at 1466 $\mathrm{cm}^{-1}$ due to saturated C-H stretching. Medium absorption band at $3081 \mathrm{~cm}^{-1}$ and weak absorption band at $1640 \mathrm{~cm}^{-}$ ${ }^{1}$ due to $=\mathrm{C}-\mathrm{H}$ stretch.

The ${ }^{1} \mathrm{H}$ NMR spectrum revealed the presence of proton signals at $\delta_{\mathrm{H}} 7.23(1 \mathrm{H}, \mathrm{dd}, J=8.1 \mathrm{~Hz}), 7.10(1 \mathrm{H}, \mathrm{dd})$ and $7.17(1 \mathrm{H}, \mathrm{dd}, J=7.4 \mathrm{~Hz})$ attributed to aromatic protons with a mono substituted phenyl ring. Signals at $\delta_{\mathrm{H}} 5.32,5.48$, 6.00 and 6.05 are due to $=\mathrm{C}-\mathrm{H}$ protons.

The ${ }^{13} \mathrm{C}$ NMR spectrum revealed a total of fifteen carbon signals. Signals at $\delta_{\mathrm{C}} 138,129.1,128.95$ and 126.5 attributed to mono substituted benzene ring, signals at $\delta_{\mathrm{C}} 128.6,127,126$ and 115 due to alkene group in the structure. The signals at $\delta_{\mathrm{C}} 33.95$ and 38.89 were assigned to aliphatic carbons and signals at $\delta_{\mathrm{C}} 43.1,36$ and 35.1 assigned for cyclic carbons. The multiplicity of each carbon atom was determined using DEPT-135 (table 3)

Based on the 1D-NMR, IR, LC-MS, HMQC and HMBC spectra the proposed structure for the compound P2 was 1-(2-(3-((E)-buta-1,3-dienyl)cyclopentyl)ethyl)benzene (See fig 2) 


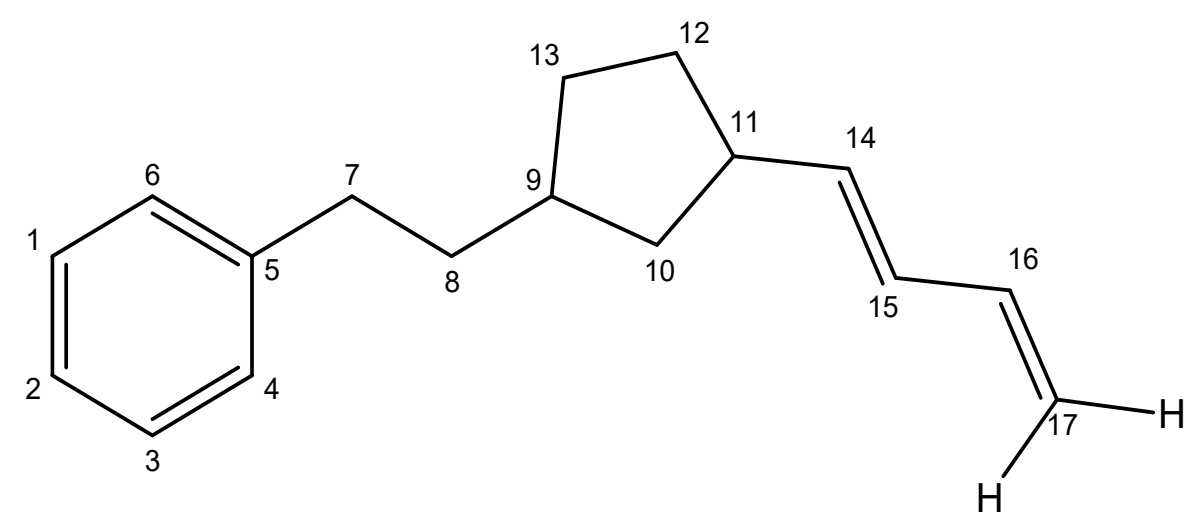

Fig. 2 The structure of compound P2

Table $3{ }^{1} \mathrm{H},{ }^{13} \mathrm{C}$ NMR and DEPT-135 spectral data of compound P2 in DMSO- $d_{6}$ and key HMBC

No. Correlation observed in HMQC $\delta_{\mathrm{H}}$

$1,3 \quad 7.23(1 \mathrm{H}, \mathrm{d}, \mathrm{d}, J=8.1 \mathrm{~Hz})$

$27.10(1 \mathrm{H}, \mathrm{d}, \mathrm{d})$

4,6 7.17(1H,d,d, $J=7.4 \mathrm{~Hz})$

5

$7 \quad 2.61(2 \mathrm{H}, \mathrm{d}, \mathrm{t}, J=5.5 \mathrm{~Hz})$

$1.62(2 \mathrm{H}, \mathrm{d}, \mathrm{t} J=5.3 \mathrm{~Hz})$

$1.54(1 \mathrm{H}, \mathrm{t}, \mathrm{t})$

$10 \quad 1.35(2 \mathrm{H}, \mathrm{d}, \mathrm{d})$

1.6(2H,d,d)

$112.2(1 \mathrm{H}, \mathrm{m}, J=14.2 \& 7 \mathrm{~Hz})$

$12 \quad 1.78(2 \mathrm{H}, \mathrm{d}, \mathrm{t})$

$2.38(2 \mathrm{H}, \mathrm{d}, \mathrm{t})$

$13 \quad 1.36(2 \mathrm{H}, \mathrm{d}, \mathrm{t})$

$14 \quad 5.48(1 \mathrm{H}, \mathrm{d}, \mathrm{d}, J=8.2 \mathrm{~Hz})$

$15 \quad 6.00(1 \mathrm{H}, \mathrm{d}, \mathrm{d}, J=10.42 \mathrm{~Hz})$

$16 \quad 6.05(1 \mathrm{H}, \mathrm{d}, \mathrm{t} J=7.45 \mathrm{~Hz})$

$17 \quad 5.32(2 \mathrm{H}, \mathrm{d} J=8.9 \mathrm{~Hz})$
Correlation observed in HMBC

DEPT-135

$$
\delta_{\mathrm{C}}
$$

128.95

126.5

129.1

138

33.95

38.89

36

43.1

43.01

36.1

35.1

126

127

128.6

115

$\begin{array}{cl}\text { C-1, C-4, C-6 } & \text { Up } \\ \text { C-1, C-3, C-4, C-6 } & \text { Up } \\ \text { C-1, C-2, C-3, C-7 } & \text { Up } \\ & \text { Quaternary } \\ \text { C-4, C-6, C-8, C-9 } & \text { Down } \\ \text { C-9, C-10, C-13 } & \text { Down } \\ \text { C-7, C-8, C-10, C-13 } & \text { Up } \\ \text { C-8, C-9, C-11, C-12 } & \text { Down } \\ & \\ \text { C-10, C-12, C-14 } & \text { Up } \\ \text { C-11, C-14 } & \text { Down } \\ \text { C-9, C-12 } & \\ \text { C-11, C-15 } & \text { Down } \\ \text { C-14, C-16 } & \text { Up } \\ \text { C-14, C-15, C-17 } & \text { Up } \\ \text { C-16 } & \text { Up }\end{array}$

\section{Characterization of compound $\mathbf{C 3}$}

Compound $\mathrm{C}_{3}$ was obtained as a yellow powdered substance from ethyl acetate extract and isolated from $n$ hexane/EtOAc (7:3) ratio, the compound was characterized as follows. Its molecular formula, $\mathrm{C}_{16} \mathrm{H}_{30} \mathrm{O}_{3}$ was determined by negative LC-MS. In the negative LC-MS spectrum, the quasi-molecular ion peak was at $\mathrm{m} / \mathrm{z} 271.02$ $[\mathrm{M}-\mathrm{H}]^{-}$.

In the IR ( $\mathrm{KBr}$ disk) spectrum showed absorption strong band of the $\mathrm{O}-\mathrm{H}$ stretch at $3434 \mathrm{~cm}^{-1}$ due to the presence of alcohol. Alkenes stretch at $3050 \mathrm{~cm}^{-1}$. Strong absorption band at $2924 \mathrm{~cm}^{-1}$ and medium absorption band at $1465 \mathrm{~cm}^{-1}$ due to saturated $\mathrm{C}-\mathrm{H}$ stretching. Strong absorption band at $1746 \mathrm{~cm}^{-1}$ due to ester group and absorption band at $1167 \mathrm{~cm}^{-1}$ due to $\mathrm{C}-\mathrm{O}$ stretching.

${ }^{1} \mathrm{H}-\mathrm{NMR} \delta_{\mathrm{H}}\left(400 \mathrm{MHz}, \mathrm{DMSO}-d_{6}\right)$ :- spectrum (table 3$)$ revealed the presence of proton signals at $\delta_{\mathrm{H}} 5.65(1 \mathrm{H}$, d) and $5.54(1 \mathrm{H}, \mathrm{dt})$ attributed to alkenes protons. Signals at 3.54(3H) due to oxygenated methylene group and signals at $\delta_{\mathrm{H}} 1.00-2.2(20 \mathrm{H}, \mathrm{m})$ due to methylene protons.

${ }^{13} \mathrm{C}-\mathrm{NMR}$ spectrum revealed a total of sixteen carbon signals. Signals at $\delta_{\mathrm{C}} 174$ due to ester carbonyl group in the structure, signal at $\delta_{\mathrm{C}} 130$ and 124 shows the presence of alkene. Signal at $\delta_{\mathrm{C}} 70.25$ assigned for carbon bearing primary alcohol. The signals at $\delta_{\mathrm{C}} 34.19,31.54,29.47,29.01,27.9,27.4,24.98$ and 22 were assigned to aliphatic carbons. The signal at $\delta_{\mathrm{C}} 27.5$ was assigned to the carbons that bearing methyl substituent. Signal $\delta_{\mathrm{C}} 55.24$ was assigned to the methyl carbon attached to oxygen. Signal at $\delta_{\mathrm{C}} 14.39$ assigned for methyl carbon. The multiplicity of each carbon atom was determined using DEPT-135 experiment. Table 4

Based on the NMR (1D) and IR spectra (table 4) the tentative structure of compound C3 was proposed as (E)-methyl 14-hydroxy-10-methyltetradec-2-enoate. (Fig 3 below) 


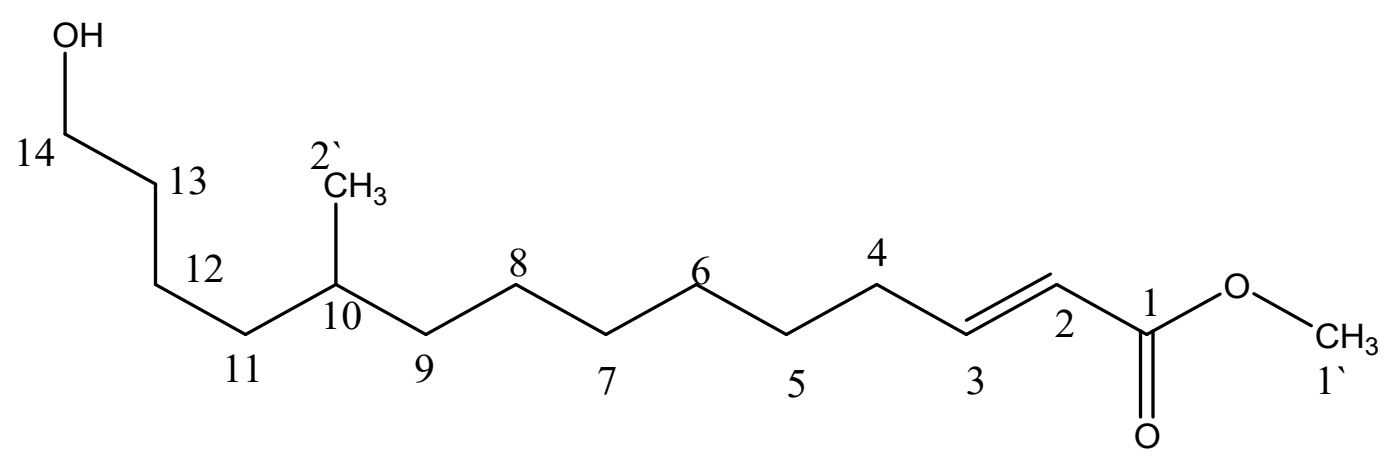

Fig. 3 The structure of compound C3

Table $4{ }^{1} \mathrm{H}$ NMR, ${ }^{13} \mathrm{C}$ NMR and DEPT-135 spectral data of compound C3 in DMSO- $d_{6}$

No
1
2
3
4
5
6
7
8
9
10
11
12
13
14
1
2

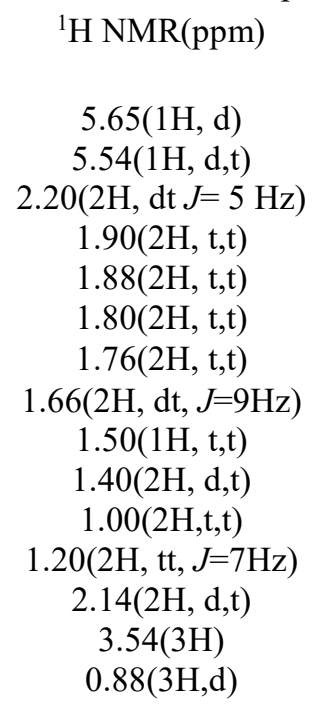

${ }^{13} \mathrm{C}$ NMR(ppm)
174
130
124
34.19
31.54
30
29.47
29.01
27.9
27.56
27.4
22
24.98
70.25
55.24
14.39

DEPT-135

Quaternary

$\mathrm{CH}$

$\mathrm{CH}$

$\mathrm{CH}_{2}$

$\mathrm{CH}_{2}$

$\mathrm{CH}_{2}$

$\mathrm{CH}_{2}$

$\mathrm{CH}_{2}$

$\mathrm{CH}_{2}$

$\mathrm{CH}$

$\mathrm{CH}_{2}$

$\mathrm{CH}_{2}$

$\mathrm{CH}_{2}$

$\mathrm{CH}_{2}$

$\mathrm{CH}_{3}$

$\mathrm{CH}_{3}$

\section{Conclusion}

The study was undertaken to investigate phytochemical screening tests, isolation and characterization of compounds from seeds extract of Calpurnia aurea. As a part of our research, we have studied its chemical constituents and chemical structure elucidation of the isolated three compounds. The isolated compounds were identified as flavonoid compound G1 named: 2-(4-(2-hydroxyethyl)phenyl)-4H-chromen-4-one, P2 from methanol extract named: 1-(2-(3-((E)-buta-1,3-dienyl)cyclopentyl)ethyl)benzene and compound C3 from ethyl acetate extract named: (E)-methyl 14-hydroxy-10-methyltetradec-2-enoate. The chemical structures of the compounds were characterized on the basis of spectral data both 1D NMR and 2D NMR techniques were used to assign the NMR signals of the isolated compounds, including ${ }^{1} \mathrm{H}$ NMR, ${ }^{13} \mathrm{C}$ NMR, HMBC, HMQC, DEPT-135 and LC-MS spectra.

\section{Acknowledgement}

Authors like to acknowledge Wolaita Sodo University for their support by providing facilities and grant required to carrying this work.

\section{References}

[1] D.L. Nelson and M.M. Cox, A.L.Lehninger Biochemistry, Worth Publishers, Inc. New York. 2005

[2] F.M. Menger, D.J. Goldsmith; L. Mandle, Organic chemistry: A Concise Approach, $2^{\text {nd }}$ Ed., 1974

[3] T.W G. Solomons, Organic Chemistry, 7th Ed., 2004.

[4] Korir et al., Afr J Tradit Complement Altern Med. (2014) 11(5):33-37

[5] Natesan Gnanasekaran et al. Ijppr.Human, 2015; Vol. 2 (2): 1-12.

[6] Shemsu et al., online, Antidiarrhoeal and Antimicrobial Activity of Calpurnia aurea Leaf Extract., Addis Ababa University, Addis Ababa, Ethiopia.

[7] Korir et al., Afr J Tradit Complement Altern Med. Isoflavones from Calpurnia aurea Subsp. aurea and their Anticancer Activity. (2014) 11(5):33-37,

[8] Haile Nega et al., IJPPR. Department of Medical Biochemistry, School of Medicine, College of Health Sciences, 
Addis Ababa University, Ethiopia. (2015)

[9] Nostro A, Germanò MP, D'angelo V, Marino A, Cannatelli MA. (2000) Extraction methods and bioautography for evaluation of medicinal plant antimicrobial activity. Lett Appl Microbiol 2000; 30: 379-384.

[10] Pradeep A, Dinesh M, Govindaraj A, Vinothkumar D, Ramesh Babu NG. Phytochemical analysis of some important medicinal plants. Int J Biol Pharm Res 2014; 5: 48-50.

[11] Saleem M, Karim M, Qadir MI, Ahmed B, Rafiq M, Ahmad B. In vitro antibacterial activity and phytochemical analysis of hexane extract of Vicia sativa. Bangladesh J Pharmacol 2014; 9: 189-93. 